competing priorities were preventing them from getting vaccinated $(9.0 \%$ vs. $2.4 \%, \mathrm{p}<0.001)$. Vaccinated participants were more likely to report that they would get a COVID-19 vaccine if recommended by public health experts $(90.5 \%$ vs. $55.9 \%, \mathrm{p}<0.001)$.

Conclusion Most paramedics believe COVID-19 vaccines to be safe and necessary. However, a sizeable proportion of paramedics reported no intention of getting vaccinated. Further analyses are needed to determine which factors influence their vaccination decisions.

\section{0-403 VALIDITY AND RELIABILITY PROPERTIES OF THE MULTIFACETED ORGANIZATIONAL HEALTH CLIMATE ASSESSMENT FOR MEASURING ORGANIZATIONAL HEALTH CLIMATE IN SERVICE, CLERICAL, AND HEALTH CARE WORKERS}

${ }^{1}$ Ryan Walsh, Ann Marie Dale, Bradley Evanoff, Ryan Colvin, Jaime Strickland. 'Washington University, United States

\subsection{6/OEM-2021-EPI.154}

Introduction Total Worker Health ${ }^{\circledR}$ programs aim to improve health climate, or employees' perceptions of support for physical and mental health from coworkers, supervisors, and upper management. Health climate is linked to physical and mental health outcomes. The recently developed Multifaceted Organizational Health Climate Assessment (MOHCA) assesses general health climate and three subfactors of workgroup, supervisor, and organizational health climate in working adults and correctional employees. There is little evidence of the MOHCA's validity and reliability properties among service, clerical, and health care workers in a large hospital system.

Objectives To investigate validity and reliability properties of the MOHCA in this sample, we examined: 1) the structural validity of the MOHCA's general and subfactor scales and 2) targeting of items to persons and measurement invariance of items among racial, sex, and income subgroups.

Methods We recruited 1,283 employees (45.9\% Caucasian; $67.7 \%$ female; $77.9 \%$ <Bachelor's degree; $32.2 \%$ annual household income $<\$ 30,000)$. We applied exploratory and confirmatory factor analyses to assess structural validity and Rasch models to assess targeting of items and measurement invariance.

Results A revised general and four-subfactor structure with workgroup, supervisor, organizational, and organizational responsiveness health climate subscales explained $73.7 \%$ of response variation with adequate reliability (Cronbach's alpha $=0.60-0.91)$. Compared with the original structure's fit, this revised structure's fit was superior (Chi-square $=33.245$, $\mathrm{df}=16$; Root Mean Square Error Approximation=0.029; Comparative Fit Index=0.997). One item demonstrated misfit to Rasch models (Infit Mean Square>1.5). Male and NonCaucasian workers were less likely to report a workgroup supportive of recovery $(\mathrm{p}<.01)$. High-income and Caucasian workers were less likely to report a workgroup that encourages use of sick days $(\mathrm{p}<.01)$.

Conclusions A revised four-subfactor MOHCA structure with a new organizational responsiveness health climate subscale demonstrated adequate validity and reliability properties to assess health climate scores among service, clerical, and health care workers in a large hospital system.
Work-Related Stress

\section{0-17 ALL-CAUSE MORTALITY AND THE TIME-VARYING EFFECTS OF PSYCHOSOCIAL WORK STRESSORS}

${ }^{1}$ Yamna Taouk, Matthew Spittal, Anthony LaMontagne. ' University of Melbourne, Australia

\subsection{6/OEM-2021-EPI.155}

Introduction The effects of poor-quality work (characterised by high job demands, low job control, job insecurity, and effortreward imbalance) are known to be harmful to health but it isn't clear whether exposure to these psychosocial work stressors over time translates into an increased risk of mortality. Objectives To examine the effect of time-varying exposures and covariates on mortality, including the effects of unemployment, not in the workforce and retirement and to investigate if gender is an effect-modifier on the relationship between long-term exposure to adverse psychosocial work stressors and mortality.

Methods Over 20,000 participants from the HILDA survey with self-reported repeated exposure measures were followed for up to 15 waves. Survival analysis models with baseline hazard specified by the Weibull distribution were used to examine the association between psychosocial work stressors over time and mortality.

Results Low job control ( $\mathrm{HR}=1.39$; 95\% CI: 1.06-1.83) and job insecurity $(1.36 ; 1.06-1.74)$ were associated with increased risk of mortality. High job demands $(1.01 ; 0.75-1.34)$ and effort-reward unfairness $(1.20 ; 0.90-1.59)$ were not associated with mortality. The effect of job insecurity was attenuated (1.20; 0.93-1.54) after controlling for sociodemographic and health risk factors. Male participants exposed to low job control and job insecurity had an $81 \%$ and 39\% increased risk of mortality, respectively, after adjustment for sociodemographic and health risk factors.

Conclusions Long-term exposure to low job control and low job security is associated with increased risk of all-cause mortality. Effects were largely restricted to males and persisted after adjustments for sociodemographic and health characteristics. Awareness of the implications of the adverse effects of psychosocial work stressors on health and mortality in workplaces, and interventions to improve job control and job security could contribute to better health and wellbeing, reducing the effect of psychosocial work stressors on mortality.

\section{0-74 WORK-RELATED PSYCHOSOCIAL RISK FACTORS FOR STRESS-RELATED DISORDERS: A SYSTEMATIC REVIEW AND META-ANALYSIS}

${ }^{1}$ Henk Van der Molen, Karen Nieuwenhuijsen, Monique Frings-Dresen, Gerda de Groene. ${ }^{1}$ Amsterdam UMC, Netherlands

\subsection{6/OEM-2021-EPI.156}

Introduction Stress-related disorders are frequently reported in the working population, with varying incidence rates of $13 \%$ for psychological distress up to $22 \%$ for emotional exhaustion with even higher prevalence rates in specific professions and countries. The objective of this systematic review and metaanalysis is to examine which work-related psychosocial risk factors are associated with stress-related disorders (SRDs). 